\title{
Chinese Five Elements Conceptual Metaphors on Time and Space
}

\author{
Di Wu \\ College of Foreign Languages \\ Hunan University \\ Changsha, China
}

\begin{abstract}
Five Element Principle occupies an important position in traditional Chinese philosophy. This paper explores the conceptual metaphors of Five Elements on time and space, which might help construe the cognitive mechanism on time and space of Chinese ancients. The analysis shows that Chinese ancients tended to understand time and space through the concrete elements which is thought as the elementary materials to construct universe. The cognitive mechanism also attributes to Chinese unique culture model Daoism.
\end{abstract}

Keywords-five elements; conceptual metaphor; embodiment; culture

\section{INTRODUCTION}

The Five Elements Principle is of significance in ancient Chinese philosophy, which is thought as the center of the Chinese traditional culture. It holds that all beings of the universe are the construction of the five elementary elements: mental, wood, water, fire and earth. Firstly, the ethos of yinyang proposed the concept of wuxing, the five elements principle to extend their interpretation of the beings to all aspects of the world. Then, by the Warring State Period, ancient Chinese developed the principle. It is stated that the five elements are not only capable of creating each other, but also can destroy each other if the balance between the connected two is broke.

According to the principle, the concept of a world is governed by the five elements: mental, wood, water, fire and earth. The relationship between the five is not only cocreating but also co-destroying. On the one hand, wood creates fire, whose ashes enrich the earth, in which metal can be found, the element with which can be used for digging well for water, which nourishes the growth of wood. One the other hand, water damps fire down, which melts metal, the one destroying wood, which erodes the earth that in turn restrains water.

In ancient China, every aspect of life is associated with the five elements. The five elements are applied to people's basic cognitive categories, such as the seasons of the year, cardinal points, colors, numbers, human organs. For example, each elements has its own responding cardinal points. Water is associated with the north, fire with the south. While, wood relates with the east. Metal is the element of the west and the earth is thought as the center. Another aspect is the five elements co-relationship with the seasons of the year. Water is connected with winter, wood with spring, metal with autumn, while, fire with summer, earth with long summer.

TABLE I. RELATIONSHIP BETWEEN FIVE ELEMENTS AND CARDINAL PoINTS (SPACE) AND SEASONS(TIME)

\begin{tabular}{|l|l|l|l|l|}
\hline metal & wood & water & fire & earth \\
\hline west & east & north & south & center \\
\hline autumn & spring & winter & summer & Long summer \\
\hline
\end{tabular}

Because of the close relationship of the cardinal points and seasons with the five elements, the five elements are always be used metaphorically to refer to the cardinal points (space) and seasons (time).

Space and time concept is imperceptible and difficult to describe directly in ancient society. As a result, ancient Chinese usually interpret the two with the help of other concrete things. The five elements principle, which constitutes Chinese fundamental way to understand the world, has presented such a figure of thought that speaks time and space by referring concrete things, which involve mental, wood, water, fire and earth. Previous studies on five elements focus on the scope of medicine, astronomy, paleography, traditional philosophy and literature. There are also several research about five elements which investigates each element's metaphor representation based on conceptual metaphor theory (Jia Dongmei \& Lan Chun 2012, 2013a, 2013 b, 2013c, 2015). However, there is still a lack of the systematic study on five elements conceptual metaphor on time and space. Hence, the present study focuses on three questions:

What's the language representation of five elements metaphor on time and space?

What cognitive mechanism lies behind the metaphoric expressions?

What cultural elements affect ancient Chinese perceiving on time and space?

\section{THEORETICAL FRAMEWORK}

A conceptual metaphor is understanding one domain of experience (that is typically abstract) in terms of another (that is typically concrete) (Kövecses). Conceptual 
metaphors are grounded in people's experience in the objective world so that they are of embodiment (Lakoff \& Johnson 1980, 1999). Metaphor - language - thinking is an organic whole: metaphor is a remarkable and universal cognitive process connecting language and concept. At the same time, people's way of thinking has a molding effect on the formation of metaphor, providing a frame and opportunity for the concept of metaphor. Metaphor comes from people's actual experience in the objective world. However, physical experience can only tell people what might be metaphors, and whether these potential metaphors can be selected as real metaphors in a given culture depends on the cultural pattern of the individual culture (Yu 1998). Metaphor is a way of thinking and language, and culture influences the physical experience of it. The connection between mind and body is not arbitrary, but based on people's cultural background, including cultural urgency, values and habits (Leung, Qiu, Ong \& Tam 2011). The cognitive nature of metaphor determines its cultural nature, and the generation and understanding of metaphor are deeply influenced by people's cultural experience (Gibbs 1999). Nations with different cultural traditions may have different metaphors for the same thing. The cultural differences embodied in metaphor can reflect the relationship between language and culture and the significant differences between different languages and cultures, and then reveal the differences in thinking and cognition of different nations.

Metaphor is a useful cognitive tool for us to conceptualize abstract categories (Ungerer \& Schmid 2001). The metaphorical relation of social group contract is represented in the language user's mind and stored in semantic memory. Metaphor is also a mirror to reflect the national way of thinking. The cultural differences in metaphor help people to understand the differences in thinking and cognition of different nations. Metaphors are embodied in the character and culture, and they are integrated with each other (Gibbs 1999). Therefore, metaphor, culture and thinking are organically linked and inseparable, and neither party can be independent from the other. Unlike English, absolute position words have a unique metaphorical projection in Chinese. This metaphorical projection has the character of body and culture, and the two permeate each other. The exploration of the conceptual metaphor system and the cognitive mechanism behind the Chinese five elements metaphor on time and space is helpful to reveal the unique thinking and cognition of Chinese people and their understanding of time and space.

\section{FIVE ELEMENTS METAPHOR ON TIME}

Time is one of the elementary dimension people apply to measure this world. However, it is also an abstract concept difficult for ancient people to talk about directly. As a result, with the five elements, fire, water, metal, wood, earth, we make this concept more specific and measurable, especially about the season concept.

\section{A. The Fire Element Metaphor on Time}

The basic fire metaphor about time mainly concerns the metaphor that "summer is fire".
- 夏气热，火也，火位在南方。《王充 论衡・难岁篇》)

Xiaqi re, huo ye, huowei zai nanfang. (Wang Chong, Lunheng. Nansui)

Summer gas is fire and the fire position lies in the south.

- 旅食白日长, 况当朱炎赫。（杜甫《白水县崔少府十九翁高 斋三十韵》)

Lv shi bairi chang, kuang dang zhuyan he. (Fu Du, the Thirty Rhymes in Baishui)

The travel day is long, let alone when the red fire is obvious.

The first "huo" in the first sentence is used metaphorically, meaning that the temperature of the summer is high. While, "zhuyan", in the second sentence, is another name of fire in ancient Chinese, referring to summer in the sentence. In both sentences, it is clear that fire, here as the source domain, maps its structure to the target domain summer, providing that summer is as hot as fire.

\section{B. The Water element Metaphor on Season}

The basic water metaphor about time mainly concerns the metaphor that "time is water". Although water co-relates with winter in the five elements principle, it is different from the "summer is fire" metaphor for "time" in this metaphor is a higher level concept which include the concept of summer because compared with the characteristics of winter, the changing characteristic of time is more close with the flowing characteristic of water.

- 时光水一般在我身上淌泻过, 我只知道身在水中, 不觉水 流。

Shiguang shui yi ban zai wo shenshang tangxieguo, wo zhi zhi shen zai shuizhong, bu jue shui liu.

Time moves pass my body like water; I only know my body is in the water, do not feel the flowing of the water.

- 逝者如斯, 而未尝往也; 盈虚者如彼, 而卒莫消长也。(苏 赋《赤壁赋》)

Shizhe ru si, er weichang wang ye; yingxuzhe ru bi, er zumo xiaozhangye. (Shi Su, Pre-ode to Chibi)

The passing of time is like this (the flowing of water), which cannot go back; the waxing and waning is like that (moon), which is decreasing and increasing mutually.

In these two sentences, passing and changing of time is conceptualized as the flowing of water. The source domain, water, maps its structure of moving to the target domain time, intending to show that the passage of time is like water flowing, which can not go back.

\section{The Metal Metaphor on Season}

The basic metal metaphor about time mainly concerns with the metaphor that "autumn is metal". In the five elements principle, metal's responding season is autumn. Consequently, there are always ideas that to speak autumn in terms of metal (jin). 
- 金风玉露一相逢, 便胜却人间无数。（秦观《鹊桥仙纤云弄 巧》) shu.

Jin feng yu lu yi xiang feng, bian sheng que ren jian wu

Meeting in such a clear and sweet autumn night, the rendezvous outshines many a worldly date. (Qin Guan Fariy of the Magpie Bridge)

- 金秋十月

Jinqiu shiyue

The October is golden autumn.

- 金天方肃杀，白露始专征。（陈子昂《送著作佐郎崔融等从 梁王东征》)

Jintian fang susha, bailu shi zhuanzheng.

Metal day (autumn) is cold and bleak; the white dew begins to dominate the world.

Jin, the metal element in five elements principle, is always connected with the autumn in Chinese. Nowadays, it is more close to the gold, which is the hyponym of metal. However, it still co-relates with time to refer to autumn. "jinfeng" in the first sentence refers to the autumn wind; while in "jinqiu" of the second sentence, "jin"is used as an adjective to modify the autumn; in the third sentence, "jintian" which literally means the metal day, is the expression used directly to refer to autumn. So, it is obvious that Chinese are used to mention autumn by referring to its corresponding element in five elements - metal.

\section{The Wood Element Metaphor on Season}

The basic wood metaphor about time mainly concerns with the metaphor that "spring is wood". Wood, as one element that constructs worlds in five elements philosophy, usually relates with spring for spring the season in which everything rouses up from sleeping. Wood is usually regarded as being of the feature of developing, growing. So the ancient Chinese, there exists metaphor that "spring is wood".

- 岁星日东方春木, 于人五常仁也, 五事貌也。

Suixing yue dongfang chunmu, yuren wuchangren ye, wushimao ye. (Book of Han Tianwenzhin)

Jupiter corresponds to the east, spring, wood, "ren" and appearance for people.

- 沉舟侧畔千帆过, 病树前头万木春。 chun.

Chenzhou cepan qianfan guo, bingshu qiantou wanmu

There are thousands of sailing boats passing by the sunken boat; there are ten thousand of woods thriving.

According to the five elements principle, the qi (gas) of spring is categorized into wood. Consequently, we sometimes use wood in terms of spring. In the second example, "mu" which means wood in Chinese, refers to spring by showing its thriving situation. However, this metaphor that "spring is wood" is no more common nowadays. It is conceived that we tend to refer to spring with the spatial word east, pronounced as "dong" in Chinese.

\section{E. The Earth in Five Elements Principle}

In the five elements principle, earth is associated with long summer. However, the usage to apply earth for long summer or any time concept is not so common. The common usage of earth is to refer to soil, people. From the nature aspect, earth is always associated with soil, land or Saturn. While, in modern Chinese, its meaning is extended to refer to something of local sense. For example, "tushengtuzhang" is Chinese is used to describe that a person is born and brought up in his hometown. "Tutoutunao" is used to describe a person's characteristic who is unfashionable and slow-witted Earth is also used metaphorically for soil that nourishes the development of culture. The reason that there are no metaphor for earth to speak of time is probably that the structures of the two domains are too different to map. Earth, as the element of stability, can not map its own structure into the time domain, which is perceived as changeable and flowing.

In this part, the five elements metaphors about the four seasons have been analyzed, which is that summer is fire, time is water, autumn is metal and spring is wood. However, we can not find the metaphors like "earth is long summer" or "earth is time" for the structures of the two domains are too difficult to map.

\section{FiVE ELEMENTS METAPHOR ON SPACE}

Time and space is the fundamental dimension we apply to measure the world. In last part, we have looked at the five elements metaphors about time from the perspective of seasons of the year. This part turns to the five elements metaphors about space.

Space is considered as three-dimensional concept, including horizontal dimension, vertical dimension and depth dimension. In this essay, we focus on the horizontal dimension of the space, especially on the five cardinal points, that is east, west, north, south and center.

It is conceived that in the five elements principle, water is associated with the north, fire with the south. While, wood relates with the east. Metal is the element of the west and the earth is thought as the center. As a result, ancient Chinese always use the basic elements to refer to the cardinal points. In the following parts, each element metaphor about space is analyzed.

\section{A. The Wood Element Metaphor on Space}

The basic wood metaphor about space mainly concerns with the metaphor that "the east is wood". The Chinese ancient philosophers propose that the east is categorized into wood element. As a result, the east is thought as the cardinal point with the characteristics of the wood. In example (8),

- 岁星日东方春木, 于人五常仁也, 五事貌也。

Suixing yue dongfang chun mu, yuren wuchang ren ye, wushi mao ye. (Book of Han Tianwenzhin) 
Jupiter corresponds to the east, spring, wood, "ren" and appearance for people.

The "east" is not only associated with wood, but also it connects with spring. As we have introduced, spring is also connected with the wood element. Consequently, people associate east with spring by creating the metaphor that "east is spring" which is more common than the basic metaphor that "east is wood". That is to say, we tend to use space to make reference to time.

- 相见时难别亦难, 东风无力百花残。(李商隐《无题》)

Xiangjianshi nan bie yi nan, dongfeng wuli baihua can. (Li Shangyin, Untitled)

It is difficult to meet and depart; the east wind is not strong that hundreds of flowers are withering.

- 东风恶, 欢情薄, 一杯愁绪, 几年离索。（陆游《钗头 凤》)

Dongfeng e, huanqing bo, yibei chouxu, jinian lusuo. (Lu You, Chaitoufeng)

The east wind is hateful and the happiness is thin. The feeling I have now is like drinking a cup of sorrow for the couple of years departing.

In those two sentences, "dongfeng", the east wind, both refers to the spring wind. What we can see from this is that in Chinese we use cardinal position terms to mention seasons. The underlying idea behind this comes from the five element metaphors about the two. That is to say, although "the east is spring" metaphor is common, its fundamental metaphor is that "spring is wood" and "the east is wood".

\section{B. The Metal Element Metaphor on Space}

The basic metal metaphor about space mainly concerns with the metaphor that "west is metal". The ancient philosophers compare west to metal and attach the attributes of metal to the west.

- 西方金也.....其神为太白, 其兽为白虎。（《淮南子・天 问训》)

Xifang jinye......qishen wei taibai, you shou baihu. (Huainanzi-Tianwenxun)

The west is metal......its body is taibai and has the beast named white tiger.

Usually, "west is metal" metaphor does not directly reflected in language, which is revised with the association of cardinal term "west" and autumn, the metal element's corresponding season. In another word, "west is autumn" is common because of the entrenchment of the two elementary metaphors "west is metal" and "autumn is metal".

- 古道西风瘦马, 夕阳西下, 断肠人在天涯。

Gudao xifeng shouma, xiyang xi xia, duanchangren zai tianya. ( Ma Zhiyuan, Tianjingsha. Qiusi)

There are ancient path, west wind, thin horse and a person with a broken heart at the end of the world.
- 昨夜西风调碧树, 独上高楼, 望尽天涯路。（晏殊《蝶恋 花》)

Zuoye xifeng diao bishu, dushang gaolou, wangjin tianya lu. (Yan Shu, Dielianhua)

Last night the wind made the green tree withered. I went up the tall building alone, seeing the end of the road toward the remote.

The "west wind" in the two sentences means the autumn wind. Both of the examples offer evidence that "west is autumn" metaphor. However, one thing needs to clarified is that this metaphor derives from the two basic metaphors "west is metal" and "autumn is metal".

\section{The Fire Element Metaphor on Space}

The basic fire metaphor about space mainly concerns with the metaphor that "south is fire".

- 夏气热, 火也, 火位在南方。(王充《论衡・难岁》

Xiaqi re, huo ye, huowei zai nanfang. (Wang Chong, Han dynasty, Lunheng. Nansui)

Summer gas is fire and the fire position lies in the south.

In this sentence, the second "huo", fire, is used metaphorically meaning south. However, this metaphor only occurs in the ancient Chinese. With the development of society, people's understanding about world changes. So the understanding about the structure of fire can not be mapped into the cardinal point south.

\section{The Water Element Metaphor on Space}

The basic water metaphor about space mainly concerns with the metaphor that "north is water". It is clear that in the five elements principle, the water element's corresponding cardinal point is north. So the ancient Chinese people apply the concrete concept of water when they speak of the north.

- 水位在北方。(班固《白虎通・五行》)

Shuiwei zai beifang. (Ban Gu, Han dynasty, Baihutong. Wuxing)

The water position lies in the north.

"Shuwei", literally meaning water position, is the spatial concept of north. However, "north is water" metaphor is not common. People usually the water element's corresponding cardinal point to make reference to its corresponding season winter.

- 北风卷地白草折, 胡天八月即飞雪。（岑参《白雪歌送武判 官归京》)

Beifeng juandi becao zhe, hutian bayue ji fei xue.(Cen Shen, Ode to the White Snow for Wu Panguan Returning to Beijing)

The north wind blows the earth, causing the breaking of the plants; it snows in August in the north barbarian region.

"Beifeng", whose literal meaning is "north wind", does not mean the wind coming from the north, but the wind in 
winter. Here, the cardinal position term north, "bei" in Chinese, is used metaphorically to allude to winter.

\section{E. The Earth Element Metaphor on Space}

According to the research, there are many of the metaphors that "the center is earth" in ancient Chinese. In those expressions, the earth element is used metaphorically to refer to the center.

- 考土中于斯色，成建都而营筑。

Kao tuzhong yu siyi, cheng jiandu er yingzhu. (Pan Yue, Ode of the West March)

This town is regarded as the center of the country; people build the capital here.

"Tuzhong" in ancient Chinese stand for the center concept. The "center is earth" metaphor is probably because the earth element co-connect the other four elements is the five elements principle for earth is fertile.

This part discusses each element metaphor on space: east is wood, west is metal, south is fire, north is water, the center is earth. Obviously most of those metaphors only occur in the poems and ancient Chinese. And some of them, such as "north is water" metaphor, are not common. People usually speak of those elements' corresponding cardinal points terms to refer to their corresponding seasons respectively.

\section{CONCLUSION}

The five elements principle reflects how Chinese people view the world. In ancient times, at first, it is difficult to distinguish the change of the four seasons and the five cardinal points for common people. So when they speak of those abstract concept, they come to the help of the five elements which is common in daily life by connecting the similarities between the elements and seasons and cardinal points. As a result, the five elements metaphors about seasons and cardinal points come in to being and are reflected in language.

Those metaphors reveal that Chinese people tend to describe some abstract changes by comprising them with some more "graspable" changes in daily life (embodiment). Moreover, the relationship between things in Chinese people's eyes is co-connected and changeable under some fundamental laws. The kernel that Chinese choose to use "five element" to understand the universe lies in Chinese unique culture model. Ancient Chinese believe that everything can be transferred by the elementary materials in nature. This is based on people's daily experience in the objective world. However, ancient Chinese's choice of using the specific elements to understand time and space originates from Chinese tradition philosophy. The feature of tradition Chinese philosophy is pictographic thinking model. Ancient philosophers connect time and space with the five materials and believe that they can transfer to each other in a circulating way, behind which lies the rule of Daoism. Dao is thought to possess the nature and form of time and space ( $\mathrm{Li}$ Xiaochun 2015).

\section{REFERENCES}

[1] Cohen, T. 1978 Metaphor and the cultivation of intimacy. Critical Inquiry 5(1), 3-12.

[2] Gibbs, Jr. R. W. T. 1999 Taking metaphor out of our heads and putting it into the cultural world. In R. W. Gibbs, Jr. \& G. J. Steen (eds.) Metaphor in Cognitive Linguistic: Selected papers from the 5th International Cognitive Linguistics Conference, Amsterdam 1997. John Benjamins Publishing Company.

[3] Kövecses, Z. 2010a. Metaphor. A Practical Introduction, 2nd edn, Oxford and New York: Oxford University Press.

[4] Lakoff, G. \& Johnson, M. 1980 Metaphors We Live by. Chicago University Press.

[5] Lakoff, G. \& Johnson, M. 1999 Philosophy in the Flesh. Basic Books.

[6] Leung, A. K., Qiu, L., Ong, L. and Tam, K. 2011 Embodied cultura cognition: Situating the study of embodied cognition in socio-cultural contexts. Social and Personality Psychology Compass 5(9), 591-608.

[7] Ning Yu. 2009 From Body to Meaning in Culture: Papers on cognitive semantic studies of Chinese. John Benjamins Publishing Company.

[8] Ungerer, F. and Schmid, H. J. 2001 An Introduction to Cognitive Linguistics. Foreign Language Teaching and Research Press.

[9] Jia Dongmei \& Lan Chun. 2012. Conceptual Metonymies and Metaphors Behind SHUI 'Water' in the five Elements[J]. Foreign Language Education. 33(6):19-33.

[10] Jia Dongmei \& Lan Chun. 2013a. Conceptual Metonymies and Metaphors Behind TU 'Earth' in the five Elements [J]. Contemporary Foreign Languages Studies. (1): 23-25.

[11] Jia Dongmei \& Lan Chun. 2013b. Conceptual Metonymies and Metaphors Behind HUO 'Fire' in the five Elements [J]. Journal of Foreign Languages. 36(5): 36-42.

[12] Jia Dongmei \& Lan Chun. 2013c. Conceptual Metonymies and Metaphors Behind JIN 'GOLD' in the five Elements [J]. Shandong Foreign Language Teaching Journal. (6): 26-32.

[13] Jia Dongmei \& Lan Chun. 2015.Conceptual Metonymies an Metaphors Behind MU 'Wood' in the five Elements [J]. Foreign Language and Translation. (1):36-41.

[14] Li Xiaochun. 2015. The Evolution of Temporal-spatial Concept in Ancient China[J]. Journal of Lanzhou University (Social Sciences) 43(3):27-33. 